\title{
Health profile and quality of life of elderly with hypertension
}

\author{
Perfil de saúde e qualidade de vida de idosas com hipertensão arterial sistêmica \\ Perfil de salud y calidad de vida de ancianos con hipertensión arterial sistémica
}

Gabriela Freire de Almeida Vitorino ${ }^{1}$, Mayara Inácio de Oliveira ${ }^{1}$, Hirla Vanessa Soares de Araújo ${ }^{1}$, Rebeka Maria de Oliveira Belo ${ }^{1}$, Thaisa Remigio Figueirêdo ${ }^{1}$, Simone Maria Muniz da Silva Bezerra ${ }^{1}$

\begin{abstract}
Objective: to evaluate the quality of life of hypertensive elderly women in the Family Health Strategy. Methods: cross-sectional, descriptive and quantitative study that evaluated 60 hypertensive older women using the tool World Health Organization Quality of Life with 26 items divided into four domains: social relations, psychological, physical and environment. Results: regarding the quality of life in all domains, except the psychological domain, the quality of life was considered regular. The psychological domain demonstrated a quality of life that needs to improve. Some questions are presented as unsatisfactory, such as the items: pain and discomfort, dependence on antihypertensive medications, negative feelings, lack of health care and recreation. Conclusion: understanding the health profile and the quality of life of hypertensive elderly women allows better knowledge about them and their adaptation to the condition imposed by the disease, offering support for planning care strategies and health education interventions.
\end{abstract}

Descriptors: Quality of Life; Health of the Elderly; Hypertension; Nursing.

Objetivo: avaliar a qualidade de vida de idosas hipertensas na Estratégia Saúde da Família. Métodos: estudo transversal, descritivo e quantitativo, avaliou 60 idosas hipertensas utilizando-se o instrumento World Health Organization Quality of Life, com 26 itens distribuídos em quatro domínios: relações sociais, psicológico, físico e meio ambiente. Resultados: em relação à qualidade de vida, em todos os domínios exceto o domínio psicológico, a qualidade de vida foi considerada regular. O domínio psicológico demonstrou uma qualidade de vida que necessita melhorar. Algumas questões se apresentaram insatisfatórias como os itens: dor e desconforto, dependência de medicamentos anti-hipertensivos, sentimentos negativos, falta de cuidados de saúde e recreação. Conclusão: compreender o perfil de saúde e a qualidade de vida de idosas hipertensas permite melhor conhecimento acerca delas e de sua adaptação à condição imposta pela doença, oferecendo subsídios para planejamento de estratégias de cuidado e intervenções de educação em saúde.

Descritores: Qualidade de Vida; Saúde do Idoso; Hipertensão; Enfermagem.

Objetivo: evaluar la calidad de vida de ancianas hipertensas en la Estrategia de Salud Familiar. Métodos: estudio transversal, descriptivo y cuantitativo, evaluó 60 ancianas hipertensas utilizándose la herramienta de la Organización Mundial de la Salud Calidad de Vida, con 26 artículos divididos en cuatro ámbitos: relaciones sociales, psicológico, físico y medio ambiente. Resultados: cuanto a la calidad de vida en todas las áreas, excepto en el dominio psicológico, calidad de vida se consideró regular. Dominio psicológico demostró calidad de vida que necesita mejorar. Algunas preguntas se presentaron insatisfactorias como artículos: dolor y malestar, dependencia de medicamentos antihipertensivos, sentimientos negativos, falta de atención de salud y recreación. Conclusión: comprender el perfil de salud y la calidad de vida de ancianas hipertensas permite mejor conocimiento acerca de ellas y su adaptación a la condición impuesta por la enfermedad, ofreciéndolas apoyo para planificación de estrategias de atención e intervenciones de educación en salud.

Descriptores: Calidad de Vida; Salud del Anciano; Hipertensión; Enfermería.

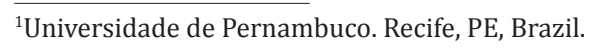




\section{Introduction}

Population aging in Brazil has been occurring quickly and intensively since the 1970 s as a result of economic development. According to estimates, by 2025 Brazil will have more than 30 million people aged 60 or older, an age group in which the person is considered elder for developing countries ${ }^{(1)}$. Among the current elderly population, about $60 \%$ are female $^{(2)}$.

Because of the increasing elderly population, the epidemiological picture on the morbidity and mortality has been changed and can be significantly related to the increase of chronic diseases ${ }^{(2)}$.

Chronic non communicable diseases, especially cardiovascular diseases, are the main cause of death in the elderly, in addition to representing high economic and social cost. One of chronic cardiovascular diseases that affects a growing number of older people around the world is the hypertension ${ }^{(1)}$.

Hypertension is a multifactorial disease characterized by high tensor levels and is defined by systolic blood pressure $>140 \mathrm{mmHg}$ and/or diastolic blood pressure $>90 \mathrm{~mm} \mathrm{Hg}$ in adults ${ }^{(3)}$. It is associated with significant morbidity, premature mortality and disability ${ }^{(2)}$.

The investigation of the physical and psychosocial impact that high blood pressure can cause can be accomplished by evaluating the quality of life of individuals, which allows a better knowledge of the patient and their adaptation to the condition imposed by the disease ${ }^{(4)}$.

Study defines quality of life as "the individual's perception of their position in life in the context of culture and value systems in which they live, and in relation to their goals, expectations, standards and concerns" ${ }^{\prime \prime}(44)$.

Quality of life is assessed by the patients themselves, and is therefore a sum of their own sensations. Considered its subjective nature, two people in the same health status may have different qualities of life, which reveals the importance of the patient being his own assessor ${ }^{(5)}$.

For an effective assessment of this quality, it was created a tool called World Health Organization Quality of Life (WHOQOL-100), which was later reduced to the abbreviated version (WHOQOLbref) and translated into Portuguese. The Brazilian Portuguese version was conducted according to the methodology recommended by WHOQOL Center and presented satisfactory psychometric characteristics ${ }^{(6)}$. Hypertension has been increasing in the population of women over 60 years of age, leading to biopsychosocial impacts. In view of this, researchers aimed at evaluating the quality of life in hypertensive elderly women in the Family Health Strategy.

\section{Method}

This is a cross-sectional, descriptive and analytical study with a quantitative approach, performed with a population aged 60 years or older, residing in the sanitary areas II and III of a basic health unit in Recife, Pernambuco State, Brazil.

According to data from the Basic Care Information System, the total population registered in both areas of the region is 12,159 people $(3,387$ families), among them 1068 are elderly, corresponding to $8.8 \%$ of this population. Of this total, 620 are female, corresponding to $58 \%$ of the elderly population.

For the sampling, it was used the convenience technique, of consecutive kind. The sample consisted of a total of 60 hypertensive elderly women enrolled in Basic Health Unit, identified during home visits. Exclusion criteria used were hypertensive elderly with cognitive impairment, not oriented in time and space, with disorganized thinking, who were not properly registered in Hiperdia Program.

Data collection was carried out in the home environment, from September to December 2012. The quality of life assessment tool, WHOQOL-bref, is selfadministered. However, due to difficulties in reading and common illiteracy among the population studied, it was decided that the researchers would apply the 
instrument.

This questionnaire is the short version of the quality of life instrument of the World Health Organization, the WHOQOL-100, translated into Portuguese and validated in Brazil ${ }^{(5)}$. It showed good psychometric performance and practicality of use and its version in Portuguese, and also adequate internal consistency, discriminant validity, criterion validity, concurrent validity and test-retest reliability ${ }^{(6)}$.

The WHOQOL-bref contains 26 questions, or aspects of life, representing facets of the four fields: social relations, psychological, physical and environment. The questions 1 and 2 are related to general quality of life and the other 24 correspond to facets that make up the domains. Each question receives scores of responses ranging from 1 to 5 , comprising a Likert scale that follows a specific assessment $^{(5)}$ proposed by the World Health Organization.

To characterize the sample, the sociodemographic (age, marital status and years of study) and clinical (body mass index, systolic and diastolic blood pressure and time of knowledge of the diagnosis of hypertension) characteristics were collected through a structured interview.

The technique considered to check blood pressure was chosen according to the VI Brazilian Guidelines on Hypertension. Blood pressure was measured three consecutive times with a minimum interval of three minutes between them, and the mean of the last two measurements was used to obtain the real blood pressure ${ }^{(3)}$. We used the digital automatic device of OMRON HEM-722C (OMRON Healthcare Inc., Kyoto, Japan), validated by the Association of protocols for the Advancement of Medical Instrumentation and Hypertesion British Society for international research $^{(6)}$.

For the analysis, blood pressure values were stratified according to the stages of hypertension, following the Brazilian guidelines on hypertension: controlled (blood pressure <140/90mmHg), hypertension stage 1 (systolic blood pressure between 140-159 and diastolic pressure between 90-99); stage 2 (systolic blood pressure between 160-179 and diastolic blood pressure between 100-109) and stage 3 (systolic blood pressure $>180$ and diastolic blood pressure $>110^{(3)}$.

The measurement of weight in the ideal range was obtained by body mass index, calculated from height and weight, considering the cutoff points of $25 \mathrm{~kg} / \mathrm{m}^{2}$ and $30 \mathrm{~kg} / \mathrm{m}^{2}$ for overweight and obesity, respectively, according to the World Health Organization, classifying the levels of the index by the risk of associated mortality ${ }^{(7)}$.

For statistical analysis, data were entered in an Excel spreadsheet and then analyzed using the Statistical Package for Social Sciences software v10.0 for Windows, and were presented by means of descriptive statistics. For analysis of the domains of quality of life and its facets, it was used a syntax proposed by the World Health Organization which considers the average response for each question that composes the domain, multiplied by 4 , resulting in a range of scores from 4 to 20 . The scores of the domains and facets were converted into analog scale from 0 to $100^{(8)}$.

To calculate the average scores, the 8 facets were divided according to the respective domains WHOQOL-BREF, where higher scores on this scale represent better quality of life. To calculate the physical domain, the values of facets were summed up and divided by 7; for the psychological domain, the values of facets were summed up and divided by 6; for the domain social relations, the values of facets were summed up and divided by 3 ; and for the domain environment the values of the facets were summed up and divided by $8^{(6)}$.

The domains are scored independently based on the assumption that the quality of life is a multidimensional construct. The score can thus range from 1 to 5 , wherein the higher the value, the better quality of life. Thus, it was considered a score of 1 to 
2.9 as need to improve, 3 to 3.9 as regular and 4 to 4.9 as good quality of life and 5 as very good ${ }^{(4)}$.

The data were extracted from the database of the Postdoctoral report entitled "Quality of life related to health among hypertensive patients in the Family Health Strategy units in Recife-PE municipality".

The study was approved by the Ethics Research Committee of the University of Pernambuco and by the Municipal Health Department of that municipality, under Protocol no. 33458.

\section{Results}

Of the 60 hypertensive elderly, the age ranged from 60 to 78 years old. Regarding marital status, $35.0 \%$ were widows and the same percentage was widows and divorced. The largest proportion (43.3\%) had five or more years of study (Table 1).

Table 1 - Sociodemographic characteristics of 60 hypertensive older women

\begin{tabular}{lll}
\hline Characteristics & $\mathbf{n}(\mathbf{\%})$ & CI*(95\%) \\
\hline Age group (years old) & & \\
$60-64$ & $21(35.0)$ & $22.93 ; 47.06$ \\
$65-69$ & $20(33.3)$ & $21.37 ; 45.22$ \\
$\geq 70$ & $19(31.6)$ & $19.84 ; 43.36$ \\
Marital status & & \\
Married/ stable union & $21(35.0)$ & $22.93 ; 47.06$ \\
Widow/divorced & $21(35.0)$ & $22.93 ; 47.06$ \\
Single & $18(30.0)$ & $18.40 ; 41.59$ \\
Years of study & & \\
0 - 4 & $17(28.3)$ & $16.90 ; 39.70$ \\
5 - 9 & $26(43.3)$ & $30.76 ; 55.83$ \\
$\geq 10$ & $17(28.3)$ & $16.90 ; 39.70$ \\
\hline Confidence interval for proportions & &
\end{tabular}

Body mass index was classified in three levels: normal, overweight and obesity. The highest percentage was observed in elderly women with normal body mass index (43.3\%), but $56.7 \%$ were overweight or obese. Body mass index, among other variables, is shown in Table 2.
Table 2 - Health profile of 60 hypertensive elderly women

\begin{tabular}{|c|c|c|c|}
\hline Characteristics & n (\%) & \multicolumn{2}{|c|}{ Average } \\
\hline Age in years & - & 61.4 & \\
\hline Weight in kilograms & - & 70.8 & \\
\hline \multicolumn{4}{|l|}{ Body Mass Index (weight/high²) } \\
\hline Normal & $26(43.3)$ & - & \\
\hline Overweight & $20(33.3)$ & - & \\
\hline Obesity & $14(23.4)$ & - & \\
\hline $\begin{array}{l}\text { Years of knowledge and diagnosis } \\
\text { of hypertension }\end{array}$ & $s$ & 9.7 & \\
\hline \multicolumn{4}{|l|}{ Years of knowledge/diagnosis } \\
\hline$<1$ & $1(1.6)$ & - & \\
\hline $1-5$ & $15(25.0)$ & - & \\
\hline $6-10$ & 13 (21.7) & - & \\
\hline$>10$ & $31(51.7)$ & - & \\
\hline $\begin{array}{l}\text { Mean of systolic blood pressure and } \\
\text { diastolic blood pressure in mmHg }\end{array}$ & & $\begin{array}{l}\text { 1st measu- } \\
\text { rement }\end{array}$ & $\begin{array}{l}\text { 2nd mea- } \\
\text { surement }\end{array}$ \\
\hline Systolic blood pressure (mmHg) & - & 137.00 & 139.47 \\
\hline Diastolic blood pressure (mmHg) & - & 82.11 & 81.58 \\
\hline
\end{tabular}

Regarding the self-assessment of quality of life, the score was 73.31, revealing a regular satisfaction with it. The domain scores were: physical (67.37), psychological (67.87), social relations (68.08) and environment (60.70). Following, the descriptive analysis obtained for each domain of the WHOQOLbref.

Regarding the physical domain, aspects of life with lower scores were pain and discomfort (26.27) and dependence on medication or treatment (42.80), which were the facets with greater disadvantage. In contrast, the aspects with less disadvantage were energy and fatigue (66.53), sleep and rest (59.75), mobility (75.00), activities of daily living (72.03) and work capacity (67.37).

In relation to the psychological domain, the aspect of life with the lowest score was negative feelings (21.19), which was the facet with greater disadvantage. Aspects of lower disadvantage were thinking, learning, memory and concentration (69.92), 
self-esteem (62.71), body image and appearance (61.86) and spirituality/religion/personal beliefs (73.31).

Regarding the domain personal relationships, scores of aspects of life represented less disadvantage: personal relationships (73.31), social support (69.92) and sexual activity (61.02).

In relation to the environmental domain, scores that showed greater disadvantage were health and social care: accessibility and quality (47.88) and participation in, and opportunities for recreation/ leisure (44.92). In contrast, those who had lowest disadvantage were physical security and protection (70.34), home environment (68.22), financial resources (51.69), opportunities to acquire new information and skills (70.34), environment physical: pollution/noise/traffic/climate (69.49) and transport (62.71).

As for the values obtained in the domains, the psychological domain had the lowest average (2.7138). The others had higher averages: physical domain (3.2857), environmental domain (3.3708), social relationships domain (3.6565). The overall score was 3.4562 , showing a regular quality of life for the elderly study (Table 3).

Table 3 - Mean and standard deviation of the sample in the evaluated domains and overall quality of life

\begin{tabular}{lc}
\hline Domain & Mean (Standart Deviation)* \\
\hline Global & $3.4562(1.84)$ \\
Physical & $3.2857(2.77)$ \\
Psychological & $2.7138(1.74)$ \\
Environmental & $3.3708(1.95)$ \\
Social & $3.6565(2.42)$ \\
\hline
\end{tabular}

\section{Discussion}

This study aimed to evaluate the quality of life of hypertensive elderly women in the Family Health Strategy. In this sense, results indicate that the population studied showed a regular satisfaction of quality of life.
The prevalence of low educational level of the sample, showing that $43.3 \%$ had not completed elementary school, and the average age of 61.43 years old are corroborated data with the findings of a similar study with hypertensive elderly women, where the prevalent level of schooling was also incomplete primary education, but the average age was higher, around 77 years of age $\mathrm{e}^{(9)}$. In relation to marital status, $65.0 \%$ of the elderly were single, widowed or divorced.

As proposed by the Ministry of Health, sociodemographic factors such as age, sex, marital status and education can affect the quality of life of the elderly ${ }^{(10)}$. Some studies have found conflicting results in the evaluation of the relationship between quality of life and age. A prevalence study conducted in 2014 showed that younger individuals had a better quality of life ${ }^{(11)}$. However, in a survey conducted in 2015, there was a better outcome among elderly individuals ${ }^{(9)}$.

The increased prevalence of hypertension occurs together with the increase of overweight and obesity in the population. Studies suggest that obesity is a major cause of hypertension, showing that approximately $78.0 \%$ of hypertension cases in men and $65.0 \%$ in women are assigned to obesity, which contributes to a poorer perception of quality of life in these patients ${ }^{(12-13)}$.

It is also observed the prevalence of percentage of 10 or more years of knowledge of diagnosis of hypertension $(51.7 \%)$, followed by 6 to 10 years (21.7\%), confirming the findings of a study carried out in $2012^{(14)}$. In a survey conducted in 2012, it was observed that, in women, the higher the time of knowledge of diagnosis of hypertension, the lower the quality of life measured by WHOQOL, especially in its total score and in the physical domain ${ }^{(15)}$. In another study, conducted in 2014, there was no statistically significant relationship between time of diagnosis of hypertension and quality of life ${ }^{(11)}$.

As for blood pressure control ( $<140 / 90 \mathrm{mmHg}$ ), the mean of the first and second measurements of systolic and diastolic blood pressure were appropriate, 
with controlled rates. The World Health Organization reports in a document for hypertension that threequarters of patients with the disease do not reach an optimal control of their blood pressure ${ }^{(10,16)}$. In Brazil, prevalence studies report that $13.0 \%$ of patients with high blood pressure under antihypertensive therapy have uncontrolled blood pressure ${ }^{(12)}$.

Evaluating the quality of life of older women through the WHOQOL-bref instrument and considering that the score 1 to 2.9 indicates the quality of life as needs to improve, 3 to 3.9 as regular, 4 to 4.9 as good and 5 as very good, it is observed that, of all domains, the psychological domain had the lowest average (2.7138), being classified as a quality of life that needs to improve.

The other domains (global, physical, environmental and social) are classified in scores between 3 and 3.9, demonstrating a regular quality of life. These results corroborate the findings of a study that evaluated the quality of life in older women and noted that in the physical, environmental, psychological and global domains these elderly women had a regular quality of life, and that the social domain had demonstrated a good quality of life ${ }^{(9)}$.

In the physical domain, $26.2 \%$ of the studied elderly had impaired quality of life regarding the item pain and discomfort, and $42.8 \%$ reported that dependence on antihypertensive medications and long-term treatment impact on their quality of life.

The analysis on the psychological domain states that $21.2 \%$ of respondents had negative feelings about their life, but the social relations domain, analyzed by the instrument in question, did not present change in quality of life.

Regarding the domains environment and overall area, considering the environment in which they live and the degree of satisfaction, it was observed lack of health care in $47.8 \%$ and recreation and leisure in $44.9 \%$.

Other studies evaluating the quality of life observed that individuals with chronic diseases such as hypertension and diabetes mellitus showed a satisfactory quality of life. In these studies some facets evaluated showed less favorable results, but they did not harm the quality of life, such as sexual activity, pain and discomfort, negative feelings, and recreation and leisure ${ }^{(17,9)}$.

By evaluating the proportion of quality of life domains, we can see that all domains had good results, especially the domain of social relations, corroborating the findings of another study that also showed good results when assessing quality of life, with highlight to the same domain ${ }^{(17)}$.

To assess the global domain of quality of life, the following questions were used: "how would you evaluate your quality of life?" And "how satisfied are you with your health?". The answers showed a degree of satisfaction of $65.9 \%$.

A study conducted in Botucatu, SP, found similar results, showing that the elderly considered health as the most important element in quality of life and the lack of it as the major reason for unhappiness ${ }^{(11)}$. In this case, there was an association between maintaining the functionality and acceptance of change, among others, and the positive changes related to aging and meanings of well-being.

Studies show the importance of existing health programs for the elderly, being necessary to know the particulars of these individuals, and especially the reasons that hinder or prevent them from performing activities that could benefit them, which is a way to promote health and the overall quality of life $\mathrm{e}^{(11)}$.

From this perspective, there must be greater interaction between the elderly women and the health teams, adding health education, because the educational practice has been increasing more and more as a strategy for health promotion, motivating individuals in order to perform activities to bring them the best living conditions and, consequently, better quality of life in aging ${ }^{(18)}$.

It must be emphasized that, as a limitation of the study, the results of this study are different because it refers to patients who belong to the units DII and DIII, who possibly are most watched clinically, 
which may have contributed, for example, for a higher frequency of patients with controlled blood pressure and a good level of overall quality of life.

\section{Conclusion}

The sociodemographic profile of hypertensive elderly assisted at the Family Health Strategy highlighted issues such as low education, average age of 61.43 years old and marital status of single and widow/divorced. It was also found a high rate of overweight and obesity, time of knowledge of diagnosis of hypertension greater than 10 years among the majority of older women and controlled mean of systolic and diastolic blood pressure to the two measurements.

Evaluation of quality of life of older women through the WHOQOL-bref showed a satisfactory quality of life in relation to most domains, with poorer performance in the psychological domain. In contrast, the results obtained through this questionnaire allowed to reveal that there is a need to improve the quality of life related to aspects of pain and discomfort, negative feelings, health and social care: accessibility and quality, participation in, and opportunities for recreation/leisure and general assessment of their health.

However, the question that addressed the evaluation of the elderly women's quality of life showed a good result, and evidences that they have consider health as an important element for a good perception of quality of life, despite the conditions and impacts imposed from high blood pressure.

Knowing the quality of life of hypertensive elderly women provides promotion of favorable conditions for building strategies by nurses to prevent diseases and promote health, focusing on answering questions, providing information and knowledge in order to provide greater autonomy to this group through interconnected actions, thus contributing to an improvement in the quality of life of this population.

\section{Collaborations}

Vitorino GFA, Araujo HVS and Figueiredo TR contributed in carrying out the literature review and writing of the article. Oliveira MI and Belo RMO contributed to critical revision of the article and the data analysis. Bezerra SMMS contributed to the final wording of the article and critical perception.

\section{References}

1. Esperandio EM, Espinosa MM, Martins MAS, Guimarães LV, Lopes MAL, Scala LCN. Prevalência e fatores associados à hipertensão arterial em idosos de municípios da Amazônia Legal, MT. Rev Bras Geriatr Gerontol. 2013; 16(3):481-93.

2. Salomão CB, Santos LC, Ferreira LD, Lopes ACS. Fatores associados a hipertensão arterial em usuários de serviço de promoção à saúde. Rev Min Enferm. 2013; 17(1):32-8.

3. Sociedade Brasileira de Cardiologia/Sociedade Brasileira de Hipertensão/Sociedade Brasileira de Nefrologia. VI Diretrizes Brasileiras de Hipertensão. Arq Bras Cardiol. 2010; 95(1 supl 1):1-51.

4. Fleck MPA. The world health organization instrument quality of the life (WHOQOL-100): Characteristics and perspectives. Ciênc Saúde Coletiva. 2000; 5(1):33-8.

5. Fleck MPA, Louzada S, Xavier M, Vieira G, Santos L, Pinzon V. Aplicação da versão em português do instrumento abreviado de avaliação de Qualidade de Vida "WHOQOL-Bref". Rev Saúde Pública. 2000; 34(2):178-83.

6. Melchiors AC, Correr CJ, Pontarolo R, Santos FOS, Souza RAP. Qualidade de vida em pacientes hipertensos e Validade corrente do MinichalBrasil. Arq Bras Cardiol. 2010; 94(3):357-64.

7. World Health Organization. Physical status: the use and interpretation of anthropometry. Geneva: World Health Organization [Internet]. 1995 [cited 2014 Out 16]. Available from: http://whqlibdoc. who.int/trs/WHO_TRS_854.pdf?ua=1. 
8. Pedroso B, Pilatti LA, Reis DR. Cálculo dos escores e estatística descritiva do WHOQOL-100 utilizando o Microsoft Excel. R Bras Qual Vida. 2009; 1(1):2332.

9. Visentin A, Mantovani MF, Caveião C, Mendes TA, Neves AS, Hey AP. Quality of life of an institution hypertensive older women long stay. Rev Rene. 2015; 16(2):218-25.

10. Ministério da Saúde (BR). Secretaria de Atenção à Saúde. Departamento de Atenção Básica. Envelhecimento e saúde da pessoa idosa. Brasília: Ministério da Saúde; 2006.

11. Mendes GS, Moraes CF, Gomes L. Prevalência de hipertensão arterial sistêmica em idosos no Brasil entre 2006 e 2010. Rev Bras Med Fam Comun. 2014; 9(32):273-8.

12. Rêgo ARON, Gomes A, Dantas EHM. Respostas da qualidade de vida de idosas hipertensas após programa de exercício físico supervisionado. Inter Science Place. 2011; 16(4):69-98.

13. Lopes ACS, Reyes ANL, César CC, Menezes MC, Santos LC. Excesso de peso entre mulheres: fatores associados. Esc Anna Nery. 2012; 16(3):451-8.
14. Bastos-Barbosa FG, Ferriolli E, Moriguti JC, Nogueira CB, Nobre F, Ueta J, et al. Adesão ao Tratamento e Controle da Pressão Arterial em Idosos com Hipertensão. Arq Bras Cardiol. 2012; 99(1):636-41.

15. Medeiros NT, Moreira TMM. Avaliação de risco coronariano, adesão terapêutica e qualidade de vida de idosos com hipertensão arterial. Rev Bras Promoç Saúde. 2012; 25(2 supl):76-82.

16. World Health Organization. Envelhecimento ativo: uma política de saúde. Brasília: Organização PanAmericana de Saúde; 2005.

17. Tavares DMS, Martins NPF, Diniz MA, Dias FA, Santos NMF. Qualidade de vida de idosos com hipertensão arterial. Rev Enferm UERJ. 2011; 19(3):438-44.

18. Fonseca GGP, Parcianello MK, Dias, CFC, Zamberlan, C. Qualidade de vida na terceira idade: considerações da enfermagem. Rev Enferm UFSM. 2013; 3(1):362-366. 